\title{
Extracellular Electron Transfer Mediated by Flavins in \\ Gram-positive Bacillus sp. WS-XY1 and Yeast Pichia stipitis
}

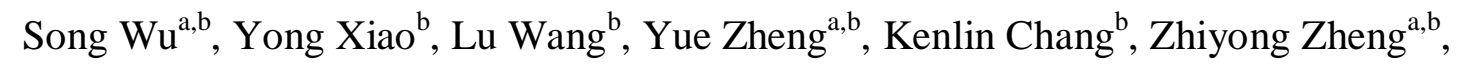
Zhaohui Yang ${ }^{\text {a,* }}$, John R. Varcoe ${ }^{\mathrm{c}}$, Feng Zhao ${ }^{\mathrm{b},{ }^{*}}$

${ }^{a}$ Key Laboratory of Environmental Biology and Pollution Control, Ministry of

Education; College of Environmental Science and Engineering, Hunan University, Changsha, 410082, China;

${ }^{b}$ Key Laboratory of Urban Pollutant Conversion, Institute of Urban Environment, Chinese Academy of Sciences, Xiamen, 361021, China;

${ }^{c}$ Department of Chemistry, University of Surrey, Guildford, GU2 7XH, United Kingdom

*Corresponding authors.

Tel/fax: +865926190766

E-mail: fzhao@iue.ac.cn; yzh@hnu.edu.cn

Postal address: Institute of Urban Environment, Chinese Academy of Sciences, Xiamen, 361021, China 


\begin{abstract}
Extracellular electron transfer (EET) of microorganisms represents a communicative bridge between the interior and exterior of the cells. Most prior EET studies have focused on Gram-negative bacteria. However, fungi and Gram-positive bacteria, that contain dense cellular walls, have rarely been reported. Herein, two model dense cell wall microorganisms (Bacillus sp. WS-XY1 and the yeast Pichia stipitis) were identified to be electrochemically active. Further analysis indicated that the two microorganisms were able to secrete flavins to mediate their EET. The discovery, that dense cell wall containing microorganisms can undertake mediated EET, adds to the body of knowledge towards building a comprehensive understanding of biogeochemical and bioelectrical processes.
\end{abstract}

Keywords: extracellular electron transfer; flavins; Gram-positive bacteria; bioelectrochemical systems; yeast

\title{
1. Introduction
}

Microbial extracellular electron transfer (EET) is a critical process occurring in the metal and carbon cycles of biogeochemical and bioenergy systems [1]. Most prior 
reports related to EET have focused on Gram-negative bacteria e.g. Shewanella sp. and Geobacter sp., whereas few Gram-positive bacteria and fungi have been reported to have EET capability [2]. Gram-positive bacteria and fungi are widespread in a broad range of aquatic and soil environments. They have been found to participate in extracellular reduction/oxidation of organic pollutants and insoluble minerals [3, 4]. Compared to Gram-negative bacteria, Gram-positive bacteria and fungi are enveloped by thicker cell walls, which can increase the stress resistance of the cells by regulating their architecture and biophysical properties [5, 6]. For example, Gram-positive bacteria have applications in high temperature and extreme $\mathrm{pH}$ environments [7-10]; whereas, studies into the EET mechanism that operates with such microorganisms have rarely reported in detail [11].

Flavins, a group of redox-active compounds, are found in most microorganisms [12]. The flavins present in Shewanella oneidensis account for $75 \%$ of the EET capacity [13]. Reduced flavins are able to dissolute the minerals goethite and hematite, which is useful for biogeochemical cycling of iron [14]. In addition, flavins can enhance hexavalent chromium reduction [15] and azo dye decolorization [16] in bioelectrochemical systems. Although flavins are secreted by many microorganisms, previous research concerning flavins mediated EET focused only on Gram-negative Shewanella spp. The mechanism of EET mediation with microorganisms that have dense cell walls has not been reported. 
In this study, a yeast and an isolated Gram-positive bacterium were selected, as a model fungus and prokaryote respectively, to investigate their EET mechanism. Although both of these model microorganisms are enveloped by dense cell walls, they were identified to be electrochemically active and to mediate EET via self-secreted flavins. These results demonstrate that flavins are ubiquitous mediators for microorganism EET and will play an important role in the application of microorganisms in geochemical mineral cycling and bioelectrochemical systems.

\section{Experimental}

\subsection{Bacteria isolation and identification}

We constructed an MFC with a micro-aerobic anode to explore the functional bacteria in it. The micro-aerobic anode was fed with sodium acetate and showed stable operation for more than one year. Bacteria were isolated from it using traditional aerobic screening technology (rather than the more commonly applied anaerobic screening technologies). Hence, an $\mathrm{O}_{2}$-tolerant Bacillus strain WS-XY1 was isolated. The dilution-to-extinction method was used and a single colony was isolated from a solid LB agar with a composition of: yeast extract (5 g L ${ }^{-1}$, Sangon, China), NaC1 (5 g $\left.\mathrm{L}^{-1}\right)$, peptone $\left(10 \mathrm{~g} \mathrm{~L}^{-1}\right.$, Sangon), and agar $\left(20 \mathrm{~g} \mathrm{~L}^{-1}\right)$. Alternating liquid incubation and plate streaking procedures were repeated three times to obtain a pure isolate. $16 \mathrm{~S}$ rRNA gene sequencing and phylogenetic analysis of the pure isolate were performed according to the method conducted by Yang [17]. Gram reaction was determined using 
a crystal violet and safranin stain. The stained cells were observed using a microscope (IX71, Olympus, Japan).

\subsection{Microbial cultivation}

Flavins are reported as components of yeast extract and mediate electron transfer between an electrode and bacteria [18]. We prepared two yeast-extract-free media in the following microbial cultivation experiments to exclude the interferences from exogenous flavins. $\mathrm{LB}(\mathrm{Y}-)$ medium consisting of peptone $\left(10 \mathrm{~g} \mathrm{~L}^{-1}\right)$ and $\mathrm{NaCl}\left(5 \mathrm{~g} \mathrm{~L}^{-1}\right)$ was used to cultivate the Bacillus sp. WS-XY1. YPD(Y-) medium consisting of

peptone $\left(20 \mathrm{~g} \mathrm{~L}^{-1}\right)$ and glucose $\left(20 \mathrm{~g} \mathrm{~L}^{-1}\right)$ was used to cultivate the Pichia stipitis. Subsequent HPLC experiments showed that no flavins were detected in these media (before cultivation of the microorganisms). The microorganisms were incubated in bed temperature incubator $(32 \square, 150 \mathrm{rpm})$.

\subsection{Electrochemical measurements}

A glassy carbon disk ( $\varnothing=3 \mathrm{~mm})$, a platinum wire, and a saturated $\mathrm{Ag} / \mathrm{AgCl}$ (3 mol $\mathrm{L}^{-1} \mathrm{KCl}$ ) were used as the working electrode (WE), counter electrode and reference electrode (RE), respectively. All the potentials presented below are vs. the saturated $\mathrm{Ag} / \mathrm{AgCl}$. The electrolyte used was aqueous phosphate buffer solution (PBS, $50 \mathrm{mmol}$ $\left.\mathrm{L}^{-1}, \mathrm{pH}=7\right)$. Stationary stage cells were harvested and then washed three times with the PBS prior to conducting electrochemical measurements. To clarify if the redox peaks originated from the reaction of compounds in the supernatant, the culture supernatant was collected for subsequent differential pulse voltammetry (DPV). As a control 
experiment, pure riboflavin (Sinopharm, China) was dissolved in the PBS and studied using DPV. The cyclic voltammetry $(\mathrm{CV})$ scan rate used was $10 \mathrm{mV} \mathrm{s}^{-1}$. For DPV studying the oxidation reactions, the staircase was $0.004 \mathrm{~V}$, the initial potential was $-0.600 \mathrm{~V}$, and the final potential was $-0.200 \mathrm{~V}$.

Chronoamperometry measurements was used to prove that the flavins are directly linked to the microbial metabolism [19]. In the three-electrode system, carbon felts were used as working and counter electrodes (surface area of $9 \mathrm{~cm}^{2}$ ), saturated $\mathrm{Ag} / \mathrm{AgCl}$ was used as $\mathrm{RE}$. The three-electrode system was placed in a single chamber reactor. The reactor was sealed by rubber seal to prevent oxygen into the chamber. During the anaerobic testing, the WE was held at $+0.300 \mathrm{~V}$ for WS-XY1 and $+0.400 \mathrm{~V}$ for P. stipitis. In the control experiment, only glucose was added (to a final concentration of $10 \mathrm{mmol} \mathrm{L}^{-1}$ when testing WS-XY1 and $50 \mathrm{mmol} \mathrm{L}^{-1}$ for P. stipitis). Experiments where both glucose and riboflavin (to a final concentration of $100 \mu \mathrm{mol}$ $\mathrm{L}^{-1}$ ) were added were used to prove that the flavins can mediate between the respiratory metabolism of these microbes and the anode.

\subsection{HPLC measurements}

Riboflavin is the precursor of flavin coenzymes (i.e. flavin mononucleotide $(\mathrm{FMN})$ and flavin adenine dinucleotide (FAD)) [20]. It can be secreted out of microbial cells $[21,22]$. Therefore, riboflavin was selected for the following analysis. Culture supernatant was collected and filtered through membrane filter of $0.22 \mu \mathrm{m}$ for HPLC analysis (Agilent, USA) [23]. 


\section{Results and Discussion}

\subsection{Gram-positive Bacillus sp. WS-XY1 and Yeast Pichia stipitis}

The presence of a certain amount of oxygen in anode chamber was reported to enhance the performance of microbial fuel cells $[24,25]$. In this work, we isolated functional microbes from micro-aerobic anode chamber to elucidate their electron transfer mechanism. 16S rRNA gene sequencing indicated that the isolate phylogenetically belongs to the Bacillus genus (Fig. 1), which has been extensively studied as the important prokaryote. It showed $100 \%$ identity with 3 strains of B. cereus (LH1, S74, 43-3) and strain B62 of B. thuringiensis. Gram reaction showed WS-XY1 was Gram-positive in accordance with that of the Bacillus genus.

Yeast is environmentally ubiquitous and is widely applied for energy production and environmental bioremediation $[3,26]$. P. stipitis is a model ethanol-producing yeast and has been thoroughly studied at the genome and protein scales. Both WS-XY1 and $P$. stipitis are enveloped by dense cell walls making them ideal candidates with which to study the EET mechanisms in such species.

\subsection{Characterization of electrochemical activity}

The redox peaks in the CVs of the microorganisms (Fig. 2A) provide the first indications that both WS-XY1 and $P$. stipitis may have electrochemical activity. It is known that $S$. oneidensis MR-1 secretes flavins to mediate EET between the cells and an electrode: the formal potential of flavins is $-0.41 \mathrm{~V}$ [27]. Abbas et al. summarized 
that both bacteria in the genus Bacillus and yeast in the genus Pichia have riboflavin excretion system [12]. Both WS-XY1 and P. stipitis yielded redox peaks at $c a$. $-0.40 \mathrm{~V}$ (the formal potential for WS-XY1 is $-0.40 \pm 0.01 \mathrm{~V}$ and for P. stipitis is $0.39 \pm 0.01 \mathrm{~V}$ ) in Fig. 2A, although these peaks were not very pronounced. Compared to CV, DPV can detect lower concentrations of redox compounds by optimization of faradaic and capacitive currents (i.e. minimizing capacitive current) [28]. This was assisted in studying the weak redox peaks in Fig. 2A (insert).

In Fig. 2B, the supernatant (microbe-free) showed similar CV oxidation peaks at ca. $-0.41 \mathrm{~V}$ (the oxidation potential for WS-XY1 is $-0.41 \pm 0.01 \mathrm{~V}$ and for P. stipitis is $-0.42 \pm 0.01 \mathrm{~V})$ : approximate to the redox potential of pure riboflavin $(-0.41 \pm 0.01)$

The small shifts in the peak potentials were originated from the small $\mathrm{pH}$ differences of the supernatant samples (Fig. 2B). Therefore, we hypothesize that the redox peaks at ca. $-0.40 \mathrm{~V}$ in Fig. 2A are, not from membrane-bound protein, due to flavins that are absorbed to cells' surfaces and are not easily washed off by PBS [1].

Shewanella oneidensis MR-1 and Geobacter sulfurreducens utilize outer-membrane MtrC and OmcA, OmcE and OmcS to reduce extracellular electron acceptor, respectively. The species investigated in this work may possess homologues of cytochromes which Shewanella or Geobacter species have; i.e. the redox peaks observed between $-0.30 \mathrm{~V}$ and $0.10 \mathrm{~V}$ may originate from some proteins associated with the cell walls $[11,29]$. In this communication, we focus on redox peaks at $c a .-0.40$ 
$\mathrm{V}$, the mechanism study of other redox peaks via molecular biotechnology with electrochemical technologies will be addressed in further work.

\subsection{Detection of secreted flavins}

Riboflavin, FMN and FAD are the main representatives of flavins. Intracellular flavins are primarily represented by the FMN and FAD in most of microorganisms, while riboflavin is main form released out of the cells to environment [31]. To confirm the hypothesis in 3.2, HPLC was employed to detect riboflavin in the supernatants during microbial cultivation. The results verified that both of the two strains secrete riboflavin [21]. These results are in good accordance with prior studies on Bacillus subtilis and yeast Candida famata, which are the mostly used microorganisms for commercial synthesis of riboflavin [32].

\subsection{Effect of flavins on EET}

Although flavins are known electron shuttles in Shewanella sp., they can't mediate EET in Escherichia coli [18]. Chronoamperometry was therefore used to further evaluate the effect of flavins on the EET of WS-XY1 and $P$. stipitis. For WS-XY1, the peak current after adding flavins was $20.5 \pm 4.3 \mu \mathrm{A}$ (Fig. 4A), which was considerably higher than the control $(6.3 \pm 2.5 \mu \mathrm{A})$. In the case of $P$. stipitis, the peak current after adding flavins was $16.3 \pm 2.5$ (Fig. 4B), again higher compared to the control $(4.9 \pm 0.8$ $\mu \mathrm{A})$. These results indicated that the flavins contribute to the respiratory metabolism of these microbes via the anode.

\section{Conclusions}


The flavins mediated EET of Gram positive Bacillus sp. WS-XY1 and the yeast $P$. stipitis (both widespread in various aquatic and soil environments) were studied. Electrochemical results indicated that both microorganisms exhibit electrochemical activity despite being enveloped by dense cell walls. Subsequent HPLC and chronoamperometry experiments proved that flavins were secreted by, and contributed to the EET with, both microorganisms. Hence, flavins are ubiquitous mediators and play important roles in mediated EET. This research will promote the understanding of biogeochemical and bioelectrical processes.

\section{Acknowledgement}

This study is supported by the National Natural Science Foundation of China (21322703, 21311130120), the Natural Science Foundation for Distinguished Young Scholars of Fujian Province (2014J06007). John Varcoe is an Engineering and Physical Sciences Leadership Fellow (EPSRC Grant EP/I004882/1).

\section{References}

[1] A. Okamoto, K. Hashimoto, K.H. Nealson, R. Nakamura, Rate enhancement of bacterial extracellular electron transport involves bound flavin semiquinones, Proc Natl Acad Sci, 110 (2013) 7856-7861. 
[2] Y. Xiao, S. Wu, Z.H. Yang, Y. Zheng, F. Zhao, Isolation and identification of electrochemically active microorganisms, Prog Chem, 25 (2013) 1771-1780. (in Chinese)

[3] H. Harms, D. Schlosser, L.Y. Wick, Untapped potential: exploiting fungi in bioremediation of hazardous chemicals, Nat Rev Micro, 9 (2011) 177-192.

[4] R. Villemur, M. Lanthier, R. Beaudet, F. Lépine, The Desulfitobacterium genus, Fems Microbiol Rev, 30 (2006) 706-733.

[5] C.J. Heilmann, A.G. Sorgo, S. Mohammadi, G.J. Sosinska, C.G. de Koster, S. Brul, L.J. de Koning, F.M. Klis, Surface stress induces a conserved cell wall stress response in the pathogenic fungus Candida albicans, Eukaryotic Cell, 12 (2013) 254-264.

[6] C. Wang, X.Q. Zhao, T. Aizawa, M. Sunairi, R.F. Shen, High aluminum tolerance of Rhodotorula sp. RS1 is associated with thickening of the cell wall rather than chelation of aluminum ions, Pedosphere, 23 (2013) 29-38.

[7] K.C. Wrighton, J.C. Thrash, R.A. Melnyk, J.P. Bigi, K.G. Byrne-Bailey, J.P. Remis, D. Schichnes, M. Auer, C.J. Chang, J.D. Coates, Evidence for direct electron transfer by a Gram-positive bacterium isolated from a microbial fuel cell, Appl Environ Microbiol, 77 (2011) 7633-7639.

[8] P. Parameswaran, T. Bry, S.C. Popat, B.G. Lusk, B.E. Rittmann, C.I. Torres, Kinetic, electrochemical, and microscopic characterization of the thermophilic, 
anode-respiring bacterium Thermincola ferriacetica, Environ Sci Technol, 47 (2013) 4934-4940.

[9] M. Liu, Y. Yuan, L.X. Zhang, L. Zhuang, S.G. Zhou, J.R. Ni, Bioelectricity generation by a Gram-positive Corynebacterium sp. strain MFC03 under alkaline condition in microbial fuel cells, Bioresource Technol, 101 (2010) 1807-1811.

[10] A. Cournet, M.L. Delia, A. Bergel, C. Roques, M. Berge, Electrochemical reduction of oxygen catalyzed by a wide range of bacteria including Gram-positive, Electrochem Commun, 12 (2010) 505-508.

[11] H.K. Carlson, A.T. Iavarone, A. Gorur, B.S. Yeo, R. Tran, R.A. Melnyk, R.A. Mathies, M. Auer, J.D. Coates, Surface multiheme $c$-type cytochromes from Thermincola potens and implications for respiratory metal reduction by Gram-positive bacteria, Proc Natl Acad Sci, 109 (2012) 1702-1707.

[12] C.A. Abbas, A.A. Sibirny, Genetic control of biosynthesis and transport of riboflavin and flavin nucleotides and construction of robust biotechnological producers, Microbiol Mol Biol Rev, 75 (2011) 321-360.

[13] N.J. Kotloski, J.A. Gralnick, Flavin electron shuttles dominate extracellular electron transfer by Shewanella oneidensis, mBio, 4 (2013).

[14] Z. Shi, J.M. Zachara, Z.M. Wang, L. Shi, J.K. Fredrickson, Reductive dissolution of goethite and hematite by reduced flavins, Geochim Cosmochim Ac, 121 (2013) $139-154$. 
[15] N. Xafenias, Y. Zhang, C.J. Banks, Enhanced performance of hexavalent chromium reducing cathodes in the presence of Shewanella oneidensis MR-1 and lactate, Environ Sci Technol, 47 (2013) 4512-4520.

[16] J. Sun, W.J. Li, Y.M. Li, Y.Y. Hu, Y.P. Zhang, Redox mediator enhanced simultaneous decolorization of azo dye and bioelectricity generation in air-cathode microbial fuel cell, Bioresource Technol, 142 (2013) 407-414.

[17] Z.H. Yang, Y. Xiao, G.M. Zeng, Z.Y. Xu, Y.S. Liu, Comparison of methods for total community DNA extraction and purification from compost, Appl Microbiol Biot, 74 (2007) 918-925.

[18] M. Masuda, S. Freguia, Y.F. Wang, S. Tsujimura, K. Kano, Flavins contained in yeast extract are exploited for anodic electron transfer by Lactococcus lactis, Bioelectrochemistry, 78 (2010) 173-175.

[19] Y.C. Wu, K. Guan, Z.J. Wang, B. Xu, F. Zhao, Isolation, identification and characterization of an electrogenic microalgae strain, PLoS ONE, 8 (2013) e73442.

[20] E. Brutinel, J. Gralnick, Shuttling happens: soluble flavin mediators of extracellular electron transfer in Shewanella, Appl Microbiol Biot, 93 (2012) $41-48$.

[21] H. von Canstein, J. Ogawa, S. Shimizu, J.R. Lloyd, Secretion of flavins by Shewanella species and their role in extracellular electron transfer, Appl Environ Microbiol, 74 (2008) 615-623. 
[22] C. Wu, Y.Y. Cheng, B.B. Li, W.W. Li, D.B. Li, H.Q. Yu, Electron acceptor dependence of electron shuttle secretion and extracellular electron transfer by Shewanella oneidensis MR-1, Bioresource Technol, 136 (2013) 711-714.

[23] E.A. Woodcock, J.J. Warthesen, T.P. Labuza, Riboflavin photochemical degradation in pasta measured by high performance liquid chromatography, $\mathbf{J}$ Food Sci, 47 (1982) 545-549.

[24] M. Rosenbaum, M.A. Cotta, L.T. Angenent, Aerated Shewanella oneidensis in continuously fed bioelectrochemical systems for power and hydrogen production, Biotechnol Bioeng, 105 (2010) 880-888.

[25] Y.Z. Fan, S.K. Han, H. Liu, Improved performance of CEA microbial fuel cells with increased reactor size, Energy Environ Sci, 5 (2012) 8273-8280.

[26] O. Schaetzle, F. Barriere, K. Baronian, Bacteria and yeasts as catalysts in microbial fuel cells: electron transfer from micro-organisms to electrodes for green electricity, Energy Environ Sci, 1 (2008) 607-620.

[27] E. Marsili, D.B. Baron, I.D. Shikhare, D. Coursolle, J.A. Gralnick, D.R. Bond, Shewanella secretes flavins that mediate extracellular electron transfer, Proc Natl Acad Sci, 105 (2008) 3968-3973.

[28] F. Zhao, R.C.T. Slade, J.R. Varcoe, Techniques for the study and development of microbial fuel cells: an electrochemical perspective, Chem Soc Rev, 38 (2009) 1926. 
[29] A. Okamoto, R. Nakamura, K. Hashimoto, In-vivo identification of direct electron transfer from Shewanella oneidensis MR-1 to electrodes via outer-membrane OmcA-MtrCAB protein complexes, Electrochim Acta, 56 (2011) 5526-5531.

[30] F. Zee, Anaerobic azo dye reduction, Ph. D. thesis. Wageningen University, Wageningen-Netherlands, 2002.

[31] V.Y. Yatsyshyn, D.V. Fedorovych, A.A. Sibirny, The microbial synthesis of flavin nucleotides: A review, Appl Biochem Micro, 45 (2009) 115-124.

[32] K.P. Stahmann, J.L. Revuelta, H. Seulberger, Three biotechnical processes using Ashbya gossypii, Candida famata, or Bacillus subtilis compete with chemical riboflavin production, Appl Microbiol Biot, 53 (2000) 509-516.

Figure captions

Fig. 1 Phylogenetic tree based on 16S rRNA gene sequences of Bacillus sp. WS-XY1.

The tree was constructed using neighbor-joining algorithm. The percentage showed at each branch is gained from 10000 bootstrap replications. 
Fig. 2 A) Cyclic voltammetry of Bacillus sp. WS-XY1 (solid line) and P. stipitis (dash line) biofilm-covered working electrodes [insert: DPV of WS-XY1 (solid line) and $P$. stipitis (dash line) biofilms]. B) DPV recorded: when $1.5 \mu \mathrm{M}$ riboflavin was added to PBS ( $\mathrm{pH}=7$, microbe-free) and with the culture medium supernatants (microbe-free) of WS-XY1 $(\mathrm{pH}=7)$ and P. stipitis $(\mathrm{pH}=7.2)$. All these tests were repeated more than 3 times under a $\mathrm{N}_{2}$ environment.

Fig. 3 The growth curve (solid line) of WS-XY1 (A) and P. stipitis (B) and the riboflavin concentrations detected in the respective microorganism-free culture supernatants (dash line). The data are averages from $n=4$ cultures.

Fig. 4 Chronoamperometry of the WS-XY1 (A) and P. stipitis (B) biofilms. The arrows indicate the addition of glucose-only (solid line) or addition of both glucose and riboflavin (dash line). 
Fig. 1

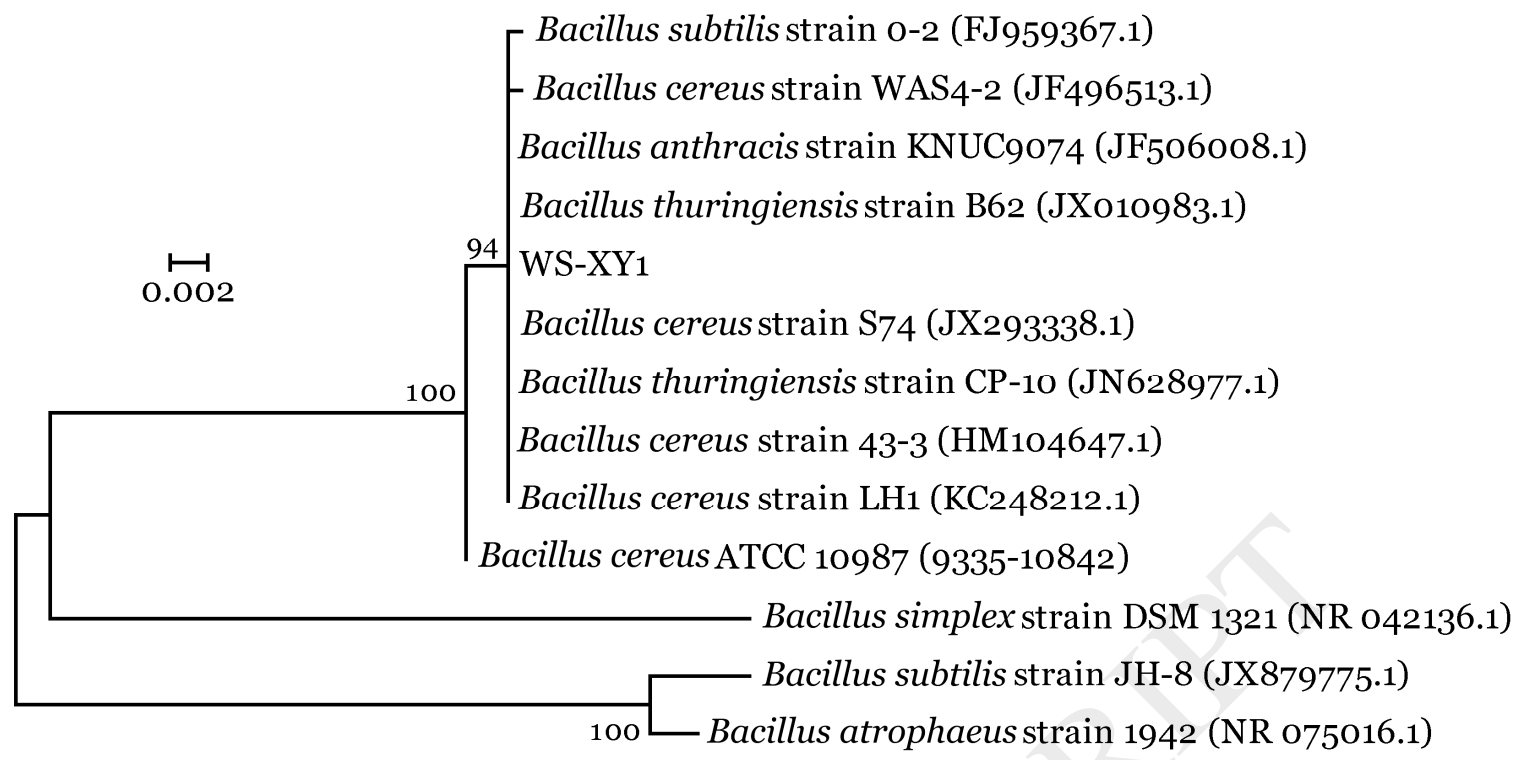


Fig. 2

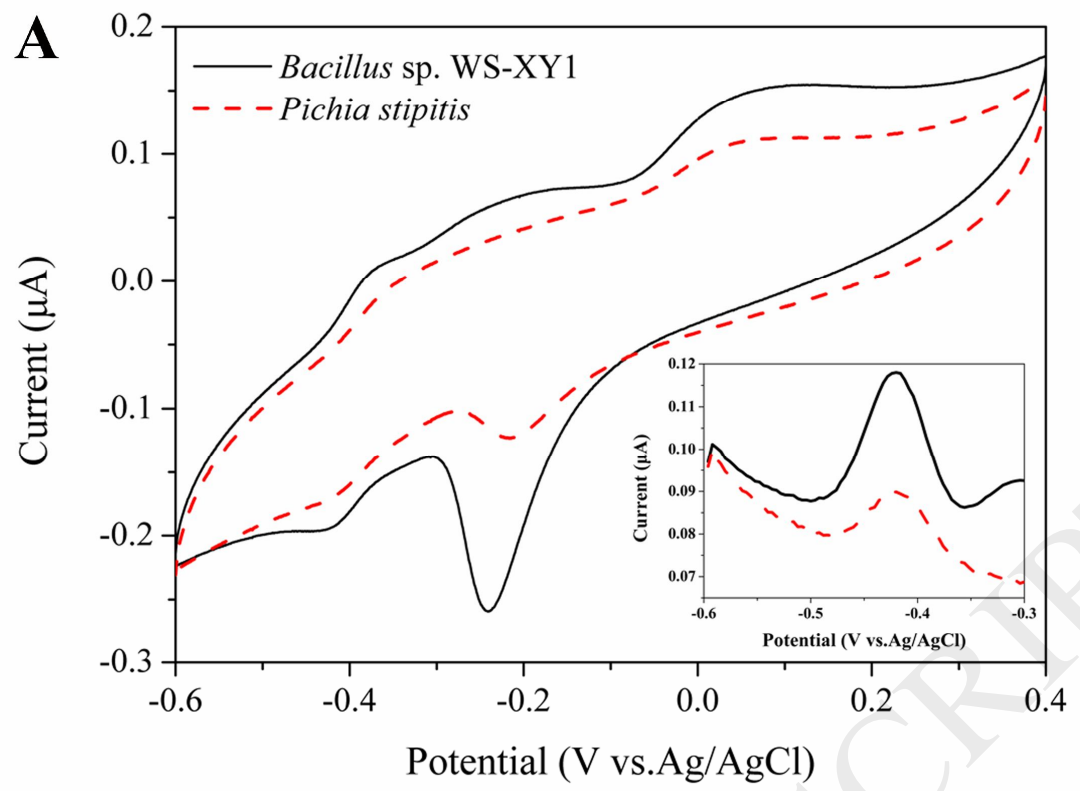

B

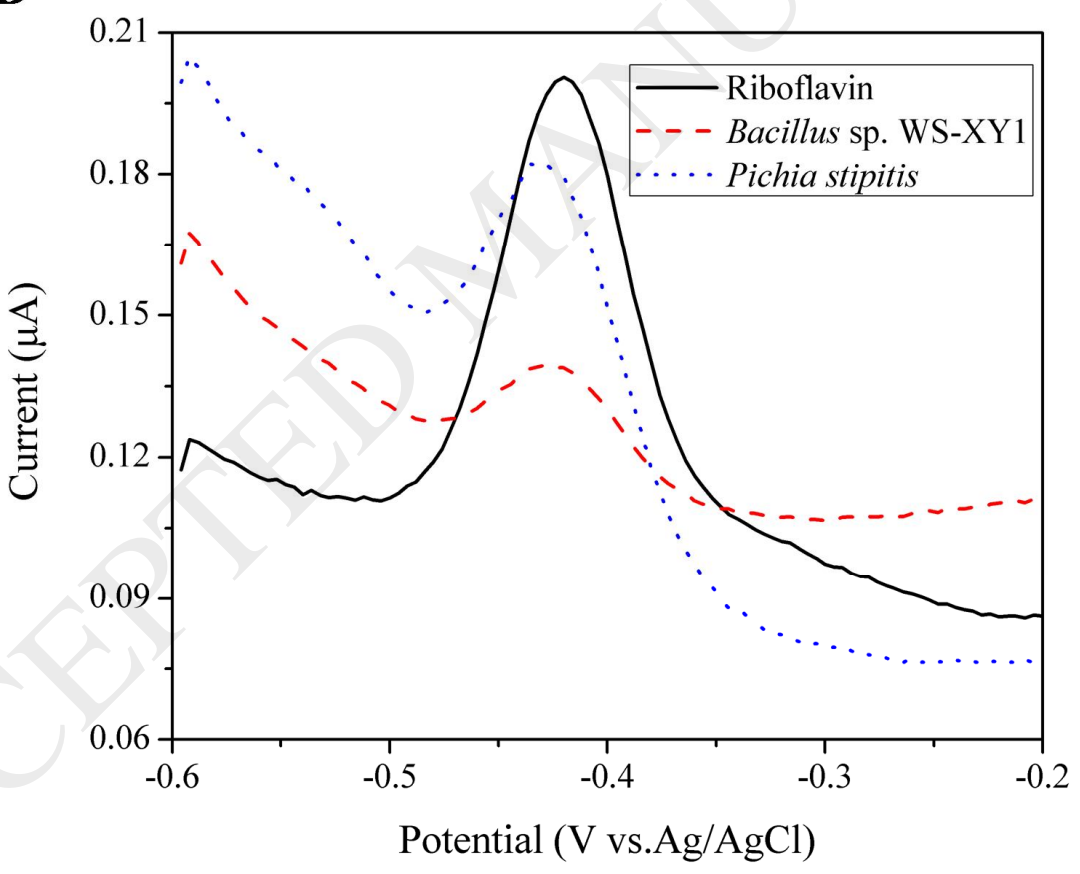


Fig. 3

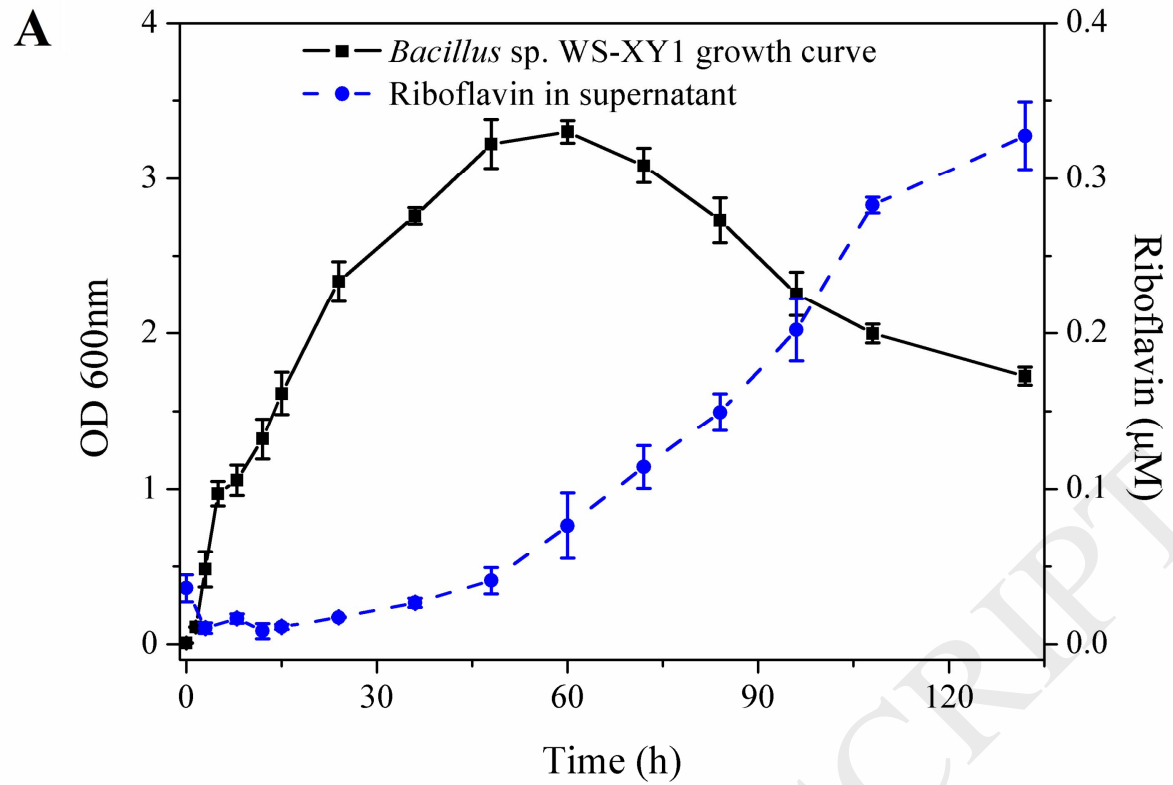

B

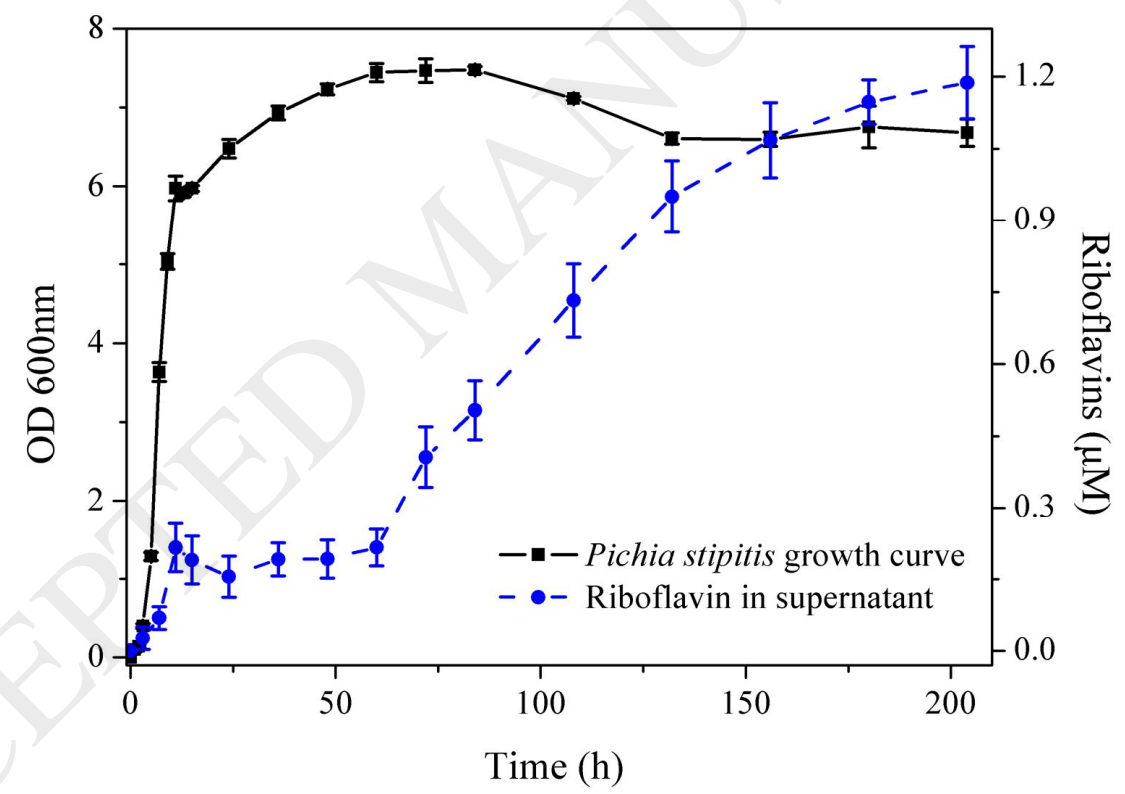


Fig. 4
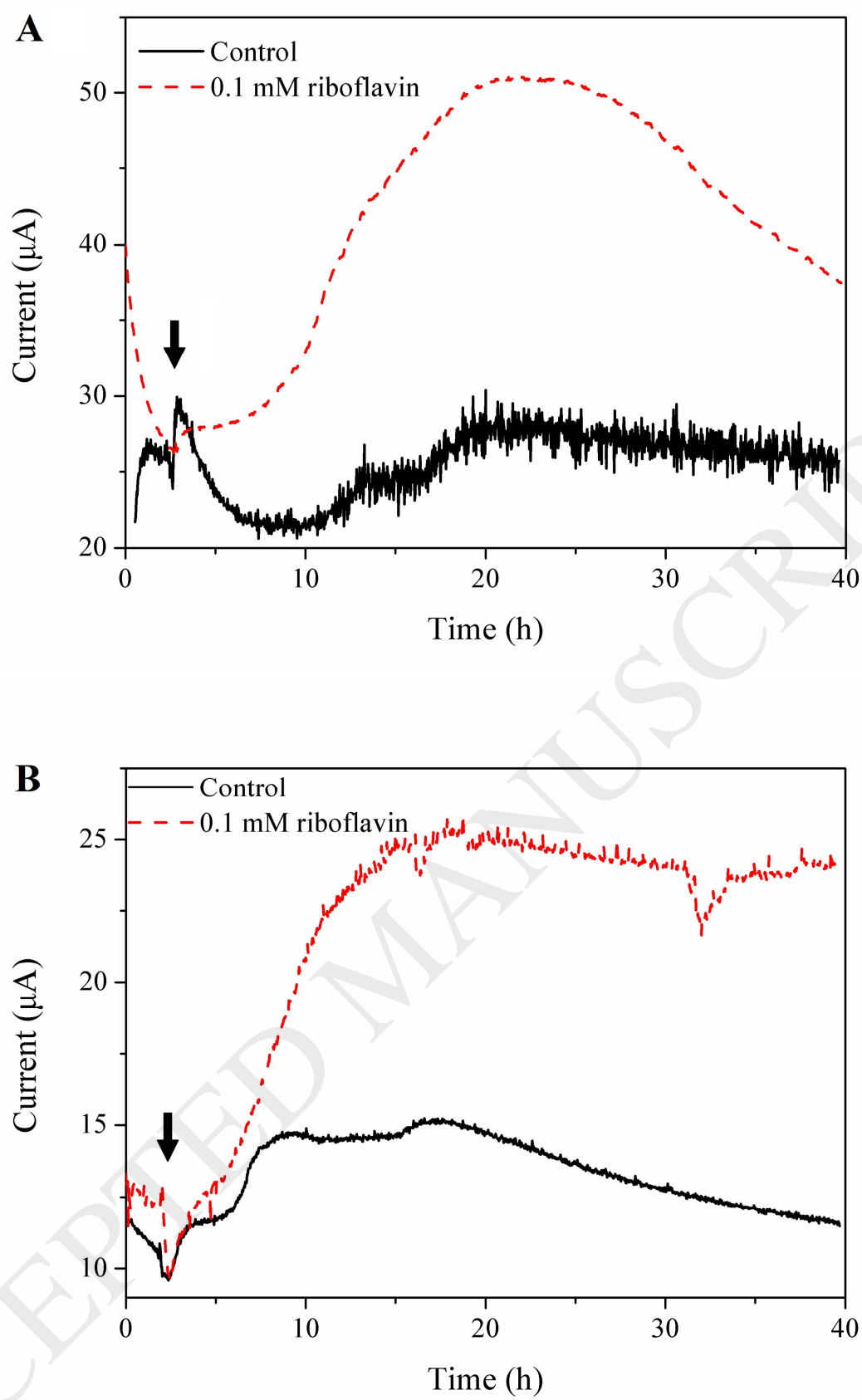